\title{
Sistema de pastejo, rotenona e controle de parasitas em bovinos cruzados: efeito no ganho de peso e no parasitismo
}

\author{
Grazing systems, rotenone and parasites control in crossbred \\ calves: effect on live weight gain and on parasites burdens \\ João B. Catto ${ }^{1 *}$; Ivo Bianchin ${ }^{1}$; Jânio M. Santurioº ; Gelson L.D. Feijón ${ }^{1}$; Armindo N. Kichel ${ }^{1}$; José M. da Silva ${ }^{1}$ \\ ${ }^{1}$ Centro Nacional de Pesquisa Gado de Corte - CNPGC \\ ${ }^{2}$ Departamento de Medicina Veterinária Preventiva, Universidade Ferderal de Santa Maria - UFSM
}

Recebido em 6 de Janeiro de 2009

Aceito em 29 de Maio de 2009

\section{Resumo}

Foram realizados dois experimentos para avaliar o controle de endo e ectoparasitos de bovinos. No primeiro avaliou-se in vitro e, em animais experimentalmente infestados, o efeito da rotenona no carrapato Rhipicephalus(Boophilus) microplus e, no segundo, avaliou-se o efeito do pastejo rotacionado e de tratamentos contra endo e ectoparasitos na carga parasitária e no desenvolvimento de animais naturalmente parasitados. In vitro a rotenona mostrou ação acaricida nas larvas e nas teleóginas, e nas larvas nos animais estabulados. Três tratamentos com endectocida, no período seco, diminuiram significativamente a contagem de ovos por grama de fezes (OPG) e o número de teleóginas, e, aumentou significativamente o ganho médio de peso. Os animais tratados com uma aplicaçáo de levamisol estavam nesse período com médias de OPG intermediárias e significativamente diferentes dos grupos controle e tratados com endectocida. $\mathrm{O}$ ganho de peso, entretanto, não diferiu significativamente do grupo controle. No período das águas, os animais tratados com fipronil estavam significativamente menos parasitados por teleóginas, mosca-dos-chifres e por larvas de Dermatobia hominis; e os tratados com rotenona. menos parasitados por mosca-dos-chifres que os animais controle. Diferentemente do esperado, os animais sob pastejo rotacionado estavam no período seco com OPG significativamente maior que os em sistema contínuo. Três tratamentos com endectocida, no período seco, e três tratamentos acaricida com fipronil, na estação chuvosa, diminuíram significativamente o OPG, o número de teleóginas e o de larvas de berne, e proporcionou um aumento significativo de $23 \mathrm{~kg}$ de peso vivo em relação aos animais não tratados.

Palavras-chave: Bezerros, ectoparasitas, nematoides, sistema de pastejo, rotenona.

\begin{abstract}
Practices for endo and ectoparasite control in beef cattle were evaluated in two independent experiments. First, the effects of rotenone on Rhipicephalus (Boophilus) microplus ticks were evaluated in vitro and in experimentally infected calves. In the second trial, the effects of grazing systems associated with endo and ectoparasite treatments on parasite burden and weight gain of naturally parasited animals were evaluated. Rotenone showed acaricide action on larvae and engorged ticks during in vitro tests and on larvae in experimentally infected calves. Three treatments with endectocide decreased $(\mathrm{P}<.05)$ the number of EPG and ticks and increased $(\mathrm{P}<.05)$ the weight gain in the dry season. Animals treated with only one application of levamisole showed EPG intermediate and different $(\mathrm{P}<.05)$ from the groups treated with endectocide (lower) and control (higher) in the dry season, but the weight gain obtained with this treatment did not differ from the control group. During the raining season the animals treated with fipronil were significantly less parasited by horn fly, tick and larvae of Dermatobia hominis and the group treated with rotenone were significantly less parasited by horn fly in relation to control. Animals under rotational grazing showed significantly higher EPG than those under continuous grazing. Three treatments with endectocide in the dry season plus three acaricide treatments with fipronil in the raining season reduced EPG, tick, and screw worm larva counts, and provided a significant increase $(23 \mathrm{~kg})$ of live weight gain in relation to untreated animals.
\end{abstract}

Keywords: Calves, ectoparasites, nematodes, grazing system, rotenone.

\footnotetext{
${ }^{*}$ Autor para correspondência: João B. Catto

Centro Nacional de Pesquisa de Gado de Corte, Embrapa, CP 154,

CEP 79002-970, Campo Grande - MS, Brazil

e-mail: catto@cnpgc.embrapa.br

Intercuf Indústria e Comércio Ltda. Campinas, SP.
} 


\section{Introdução}

O sistema produtivo gado de corte no Brasil está alicerçado na pastagem e o principal problema no desenvolvimento dos animais é a variação estacional na sua qualidade e disponibilidade. Na maior parte do território brasileiro ocorre uma diminuição na oferta e na qualidade do pasto durante os meses mais secos e frios (abril/maio a setembro/outubro). Este é o período indicado para o controle dos nematódeos gastrintestinais, entre o desmame e dois anos de idade, por causa do baixo nível nutricional das pastagens, e os animais não terem ainda desenvolvido resistência e/ou tolerância aos parasitas (BIANCHIN et al., 1995; 2007).

Com o aparecimento crescente de resistência do carrapato Rhipicephalus (Boophilus) microplus aos acaricidas de síntese e o perigo associado à contaminação ambiental e dos alimentos, tem aumentado a procura pelo controle alternativo dos ecto e endoparasitas, entre eles a fitoterapia e o diferimento da pastagem em sistemas de pastejo rotacionado.

A rotenona, princípio ativo presente em vários gêneros de plantas, é conhecida como inseticida e acaricida desde a Idade Média. Nas primeiras décadas do século passado, essas plantas eram cultivadas na América do Sul, África e Ásia, mas caíram em desuso com o advento dos inseticidas clorados e fosforados. O pastejo rotacionado vem sendo investigado no controle das nematodoses gastrintestinais de bovinos e ovinos no Brasil (FERNANDES et al., 2004; SOUZA et al., 2006; ROCHA et al., 2008). O uso desta prática, no entanto, sem o conhecimento da epidemiologia da doença, em cada região, pode não ter efeito ou mesmo agravar o problema (EYSKER et al., 1993; HAMMOND et al., 1997). Apesar de recomendado na pecuária orgânica, não há resultados experimentais ou estudos de casos que tenham demonstrado seu efeito no controle dos nematódeos gastrintestinais de bovinos no Brasil (CATTO; BIANCHIN, 2007).

O objetivo deste estudo foi avaliar in vitro e in vivo o efeito acaricida da rotenona de raiz de Lonchocarpus nicou, (Deguelia utilis comb. nov, TOZZI, 1998) sobre o R.(B.) microplus, e o efeito do pastejo rotacionado e de tratamentos anti-helmínticos e acaricidas no parasitismo e no ganho de peso de bovinos cruzados, em um sistema intensivo de terminaçáo a pasto.

\section{Material e Métodos}

Antes da utilização no ensaio a campo, o efeito carrapaticida da rotenona foi avaliado in vitro em larvas e em teleóginas; e, in vivo, em animais estabulados, experimentalmente infestados. Foram realizados dois testes de envelope com larvas (FAO, 1971). Foram adicionados $25 \mathrm{~g}$ do produto Intercuf ${ }^{\circledast}$ em $100 \mathrm{~mL}$ de etanol, na temperatura ambiente, por 24 horas em ambiente escuro. Após esse período, foram adicionados $2 \mathrm{~L}$ de água (concentração final de $12 \mathrm{mg} \cdot \mathrm{mL}^{-1}$ ). Foram coletados $3 \mathrm{~mL}$ da solução em papel filtro de $105 \mathrm{~cm}^{2}$, ao qual foram adicionados aproximadamente 100 larvas de 14 dias de idade. Foram feitas três repetiçóes em cada teste e, como controle, solução $5 \%$ de álcool etílico/água. A leitura de larvas vivas e mortas (\%) foi realizada após 24 horas.
Com teleóginas, foram realizados três testes de imersão (DRUMMOND et al., 1973), com duas repetiçôes em cada teste e 10 teleóginas em cada repetição. A rotenona foi testada na mesma concentração e, como controle, utilizou-se solução 5\% de álcool etílico/água.

Para o teste in vivo, 10 bezerros cruzados (Bos taurus $\times$ Bos indicus) recém-desmamados, tratados com acaricida de ação curta, foram mantidos em baias individuais por 15 dias. Após esse período, todos os animais foram infestados com 20.000 larvas de $R$.(B.) microplus, de aproximadamente 14 dias de idade. Quatro dias após a infestação, cinco animais foram aleatoriamente tratados com rotenona $\left(\mathrm{G}_{1}\right)$ e cinco mantidos como controle $\left(\mathrm{G}_{2}\right)$. O produto Intercuf foi preparado como descrito acima, e imediatamente, aplicados $4 \mathrm{~L} \mathrm{em}$ cada animal com pulverizador costal. Todas as teleóginas produzidas em cada animal foram coletadas diariamente, pesadas e mantidas em estufa para quantificar a ovopostura e estimar a taxa de eclosão.

$\mathrm{O}$ inicio da queda das teleóginas da primeira infestação foi no $21^{\circ}$ dia. Seis dias após, os animais dos dois grupos foram novamente infestados com 5.000 larvas e, os do grupo $\mathrm{G}_{1}$, novamente tratados três dias após a segunda infestação. Os procedimentos para coleta, contagem e pesagem das teleóginas e da ovopostura, e a estimativa da taxa de eclosão foram repetidos.

\section{Ensaio a campo}

O experimento foi realizado no Centro Nacional de Pesquisa de Gado de Corte, EMBRAPA, Mato Grosso do Sul. O clima da região é uma transição entre Cfa e o subtipo Aw com estação chuvosa na primavera/veráo e seca no inverno. A média anual de precipitação pluviométrica é $1550 \mathrm{~mm}$ e a temperatura média mensal acima de $17^{\circ} \mathrm{C}$.

Foram realizados três ciclos experimentais de um ano (maio de 2002 a junho de 2005), utilizando-se, em cada ciclo, 192 bezerros desmamados de 7 a 9 meses de idade. No primeiro ciclo, foram utilizados bezerros Brangus e, nos dois posteriores, bezerros Brangus e Braford. A pastagem de Brachiaria brizantha, com 20 anos de formação, foi recuperada antes de iniciar o experimento com aplicaçóes de adubos corretivos na superfície. Foram aplicadas 3 t.ha ${ }^{-1}$ de calcáreo dolomítico (PRNT 75\%) e 80 kg.ha ${ }^{-1}$ de $\mathrm{P}_{2} \mathrm{O}_{5}$ solúvel e, anualmente, como adubação de manutenção, aplicaram-se $50 \mathrm{~kg}$ de N.ha ${ }^{-1}, 25 \mathrm{~kg}$ de $\mathrm{P}_{2} \mathrm{O}_{5}$ e $50 \mathrm{~kg}$ de $\mathrm{K}_{2} \mathrm{O}$ na primavera; e $45 \mathrm{~kg}$ de N.ha ${ }^{-1}$ no verão.

A área de 64 ha foi subdividida em quatro sistemas de pastejo rotacionado com seis divisóes de 2 ha, com praça de alimentação em cada sistema e período de pastejo de 6 dias, e, 8 piquetes para pastejo contínuo de 2 ha com fornecimento de água e ração em cada piquete. Quatro tratamentos foram avaliados nos dois sistemas de pastejo e com duas repetiçóes espaciais no sistema contínuo: $\mathrm{C}_{1}$ e $\mathrm{R}_{1}$ - controle, não tratados contra endo e ectoparasitas; $\mathrm{C}_{2}$ e $\mathrm{R}_{2}$ - tratados com uma aplicação de levamisol, apenas no início de cada ciclo, e com três tratamentos acaricida (rotenonaIntercuf ${ }^{\circledast}$ ), a cada 21 dias, a partir de outubro; $\mathrm{C}_{3}$ e $\mathrm{R}_{3}$ - tratados com endectocida, em maio, julho e setembro, e com acaricida como no $\mathrm{C}_{2}$ e $\mathrm{R}_{2}$. Além disso, no pastejo contínuo avaliou-se o tratamento $\mathrm{C}_{4}$ - tratado com endectocida, como no $\mathrm{C}_{3}$ e $\mathrm{R}_{3}$ e com três tratamentos de fipronil a cada 21 dias a partir de outubro e, 
no pastejo rotacionado, o tratamento $\mathrm{R}_{4}$ - tratado com levamisol, como no $\mathrm{C}_{2}$ e $\mathrm{R}_{2}$ e com acaricida, como no $\mathrm{C}_{4}$ (Tabela 1 ).

Em cada tratamento/repetiçáo foram alocados, aleatoriamente, após estratificação por peso e raça (ano 2 e 3), 6 animais com peso médio aproximado de $200 \mathrm{~kg}$ em cada repetição do pastejo contínuo e 36 no pastejo rotacionado. Como o objetivo do sistema era fazer a terminaçáo em um ano, os animais foram arraçoados nos quatro meses iniciais (junho a setembro) com $1 \mathrm{~kg}$ de ração animal/dia e, na fase final, fevereiro a maio, com $3 \mathrm{~kg} / \mathrm{animal} / \mathrm{dia}$. A ração, no período seco, era composta com milho triturado (60\%), farelo de soja $(34 \%)$ mistura mineral $(3 \%)$, ureia $(2,5 \%)$, sulfato de amônio $(0,4 \%)$ e rumensin $(0,1 \%)$; e, na fase de terminação, milho triturado $(78 \%)$, farelo de soja $(18,5 \%)$ mistura mineral $(2 \%)$, ureia $(1,25 \%)$, sulfato de amônio $(0,2 \%)$ e rumensin $0,05 \%)$.

A cada 28 dias, os animais foram pesados, ocasião em que houve coleta de fezes para contagem de ovos de nematódeos (OPG) (GORDON; WHITLOCK, 1939), coproculturas (ROBERTS; O`SULLIVAN, 1950), contagem do número de mosca-dos-chifres (BIANCHIN; ALVES, 2002), carrapato (WHARTON; UTECH, 1970) e de larvas de Dermatobia hominis na superfície total de cada animal. Simulando o pastejo, larvas infectantes de nematódeos foram recuperadas da pastagem antes da entrada dos animais em uma das divisóes dos tratamentos em pastejo rotacionado, e, simultaneamente, em uma das repetiçóes dos tratamentos em pastejo contínuo. Após a separação por lavagem e sedimentação (CATTO; BIANCHIN, 2007), as larvas foram, contadas, identificadas segundo Keith (1953) e o número expresso em larvas. $\mathrm{kg}^{-1}$ de matéria seca (MS). A precipitação pluviométrica e a temperatura do ar foram coletadas em uma estação distante aproximadamente $2 \mathrm{~km}$ da área experimental e a produção de MS da pastagem foi avaliada em seis ocasióes e estimada com base na massa foliar e na massa de talos.

\section{Análise estatística}

O OPG e o número de moscas, bernes e carrapatos foram transformados usando-se a função $\mathrm{LOG}_{10}(\mathrm{y}+1)$ para normalizar a distribuição dos dados. A análise de variância foi utilizada para a avaliação dos resultados por meio do procedimento GLM do SAS Institute (1989), e as médias comparadas, usando-se o teste $T$ ou $F$.

Pelo fato de todos os tratamentos não se repetirem nos dois sistemas de pastejo, o efeito de tratamento no ganho de peso, no OPG, e no número de ectoparasitos foram comparados inicialmente como blocos ao acaso, utilizando-se o seguinte modelo estatístico da Equação 1:

$$
y=\mu+T_{j}+B_{k}+\operatorname{ano}_{1}+\varepsilon
$$

Onde: $\mu=$ média geral da variável avaliada; $T=$ efeito fixo de tratamento; $B$ = efeito fixo de raça; $a n o$ = efeito fixo de ano; e $\varepsilon=$ Erro aleatório associado a cada observação.

Posteriormente, para avaliar o efeito de sistema do pastejo e os efeitos isolados dos tratamentos anti-helmínticos ou endectocida, no período de seca, e dos tratamentos acaricidas, na estação chuvosa, aplicou-se a análise de contrastes. Os seguintes contrastes foram avaliados; " $\mathrm{C}_{2}$ e $\mathrm{R}_{2}$ vs. $\mathrm{C}_{3}$ e $\mathrm{R}_{3}$ ”, para comparar o uso de apenas uma dose de anti-helmíntico com três doses de endectocida; " $\mathrm{C}_{1}, \mathrm{C}_{2} \mathrm{e}$ $\mathrm{C}_{3}$ vs. $\mathrm{R}_{1}, \mathrm{R}_{2}$ e $\mathrm{R}_{3}$ ”, para avaliar efeito de sistema de pastejo; " $\mathrm{C}_{3} \mathrm{e}$ $\mathrm{R}_{2}$ vs. $\mathrm{C}_{4}$ e $\mathrm{R}_{4}$ ”, para comparar o efeito da rotenona com fipronil e " $\mathrm{C}_{2}$ e $\mathrm{R}_{2}$ vs. $\mathrm{C}_{1}$ e $\mathrm{R}_{1}$, para comparar o efeito da rotenona com o grupo controle. Por último, nos animais sob pastejo rotacionado, foram comparados os tratamentos $\mathrm{R}_{1}, \mathrm{R}_{2}$ e $\mathrm{R}_{4}$, para avaliar o efeito dos tratamentos acaricidas, durante a época das águas.

\section{Resultados}

\section{Ensaios com rotenona in vitro e em animais estabulados contra R.(B.) microplus}

Nos testes de envelope, a percentagem de mortalidade das larvas de $R$. (B.) microplus tratadas com rotenona foi de $84,5 \pm 4,5 \%$ e $77,2 \pm 3,0 \%$ e, no controle, $0 \%$ e $0,3 \% \pm 0,5 \%$, respectivamente. Nos três testes de imersão com teleóginas, a eficiência acaricida foi de $60,7,70,9$ e 48,9\% e o efeito ocorreu principalmente pela diminuição da ovopostura e da embriogênese.

Nos animais estabulados, nenhuma teleógina foi produzida nos animais tratados $\left(G_{1}\right)$ nas três infestaçóes experimentais. $\mathrm{Na}$ primeira infestação, o grupo controle $\left(\mathrm{G}_{2}\right)$ produziu 1.132 teleóginas (25,1 tel/animal/dia); na segunda 64 (4 tel/animal/dia); e, na terceira, 139 (8,6 tel./animal/dia). O peso médio das teleóginas (g), peso médio da ovopostura (g) e a eclodibilidade média (\%) da primeira, segunda e terceira infestaçóes no grupo controle $\left(\mathrm{G}_{2}\right)$ foi: $0,233,0,249,0,248 ; 0,130,0,131,0,135$ e 97,7, 82,1 e $94,6 \%$, respectivamente.

Tabela 1. Arranjo experimental (tratamentos) e número mínimo de dados disponíveis (repetiçôes) por ano de avaliação.

\begin{tabular}{lcccccccc}
\hline \multicolumn{1}{c}{ Pastejo } & \multicolumn{2}{c}{ Contínuo } & \multicolumn{3}{c}{ Rotacionado } \\
\hline Tratamentos & $\mathbf{C}_{\mathbf{1}}$ & $\mathbf{C}_{\mathbf{2}}$ & $\mathbf{C}_{\mathbf{3}}$ & $\mathbf{C}_{\mathbf{4}}$ & $\mathbf{R}_{\mathbf{1}}$ & $\mathbf{R}_{\mathbf{2}}$ & $\mathbf{R}_{\mathbf{3}}$ & $\mathbf{R}_{\mathbf{4}}$ \\
\hline Período seco $^{1}$ & Controle & Levamisol & Estratégico & Estratégico & Controle & Levamisol & Estratégico & Levamisol \\
Período chuvoso $^{2}$ & Controle & Rotenona & Rotenona & Fipronil & Controle & Rotenona & Rotenona & Fipronil \\
Ano 1 & 12 & 12 & 12 & 12 & 35 & 36 & 36 & 36 \\
Ano 2 & 12 & 12 & 12 & 12 & 36 & 36 & 36 \\
Ano 3 & 12 & 11 & 12 & 12 & 35 & 36 & 36 \\
\hline
\end{tabular}

"Tratamento contra endoparasitas e ectoparasitas, no qual "levamisol" indica aplicação de uma única dose de produto a base de levamisol no mês de maio e "estratégico" indica aplicaçóes de endectocida nos meses de maio, julho e setembro, conforme Bianchin et al., 1995; 2007; ${ }^{2}$ Tratamento contra ectoparasitas, três tratamentos em intervalos de 21 dias no início da estaçăo chuvosa. 


\section{Ensaio a campo contra nematódeos intestinais, carrapatos e moscas do chifre}

As médias da precipitação pluviométrica e da temperatura média no período seco (maio a setembro) e chuvoso (outubro a abril), foram muito próximas das médias dos últimos 20 anos, exceto no segundo ciclo, quando a precipitação foi maior no período seco e menor na estação chuvosa (Tabela 2).

No primeiro ciclo, houve tendência da produção de MS no pastejo contínuo ser maior nas folhas e menor nos talos. Posteriormente, a produção de MS nas folhas foi semelhante nos dois sistemas de pastejo e maior nos talos no pastejo contínuo. A produçáo total de MS oscilou entre 6 a 8 t.ha ${ }^{-1}$ durante o período experimental (Figura 1).

Das larvas coletadas na pastagem, 83,1, 14,0, 1,7 e 1,2 \% pertenciam aos gêneros Cooperia, Haemonchus, Oesophagostomum e Trichostrongylus, respectivamente. Os números de larvas infectantes, náo avaliados estatisticamente, foram sempre baixos (entre 0 e $150 \mathrm{~L}_{3}$. $\mathrm{kg}^{-1}$ de MS) e próximos no pastejo contínuo e rotacionado, e, entre os tratamentos avaliados. Nas coproculturas foram identificadas larvas infectantes dos gêneros Cooperia (65 a 35\%), Haemonchus (35 a 65\%), Trichostrongylus (0 a 2\%) e Oesophagostomum (3 a 7\%). $\mathrm{O}$ sistema de pastejo não modificou a proporção dos gêneros mas houve tendência nos dois sistemas de diminuir a proporção das larvas de Cooperia e aumentar as de Haemonchus entre o primeiro e o terceiro ciclo.

A médias de parasitismo, nos três ciclos nos grupos de animais controle, no pastejo contínuo e rotacionado, foram: OPG - $216 \pm 132$ e $235 \pm 141$; teleóginas $-10,7 \pm 9,2$ e $11,8 \pm 14,4$; mosca-doschifres $-82 \pm 45$ e $87 \pm 48$ e larvas de berne $-3,3 \pm 3,9$ e 2,3 $\pm 2,4$, respectivamente. Independentemente do sistema de pastejo, o ganho de peso foi de $298 \mathrm{~g} / \mathrm{animal} / \mathrm{dia}$ no período seco; e de 572 g/animal/dia no período chuvoso.

$\mathrm{Na}$ análise inicial dos tratamentos como blocos ao acaso, o efeito dos tratamentos com endectocida $\left(\mathrm{C}_{3}, \mathrm{C}_{4}\right.$ e $\left.\mathrm{R}_{3}\right)$, no período seco, foi significativo no OPG e no número de teleóginas, com as menores médias ocorrendo nesses tratamentos (Tabela 3). Os grupos $\mathrm{C}_{3}$ e $\mathrm{C}_{4}$ estavam também, nesse período, menos parasitados por mosca-dos-chifres mas, no pastejo rotacionado, a média do tratamento $\mathrm{R}_{3}$ não diferiu dos demais (Tabela 3).

Os tratamentos $\mathrm{C}_{3}$ e $\mathrm{C}_{4}$ tiveram, respectivamente, a menor e a maior média de infestação por larvas de $D$. hominis no pastejo contínuo e, no pastejo rotacionado, a média do tratamento $\mathrm{R}_{3}$ não diferiu significativamente dos demais.

Tabela 2. Médias da precipitação pluviométrica e da temperatura média no período seco (abril a setembro) e chuvoso (outubro a março), Campo Grande, Mato Grosso do Sul.

\begin{tabular}{lcccc}
\hline & \multicolumn{2}{c}{$\begin{array}{c}\text { Precipitaçáo } \\
\left(\mathbf{m m}^{3}\right)\end{array}$} & \multicolumn{2}{c}{$\begin{array}{c}\text { Temperatura } \\
\text { média }\left({ }^{\circ} \mathbf{C}\right)\end{array}$} \\
\hline & Seca & Chuva & Seca & Chuva \\
\hline Média 20 anos & 322 & 1218 & 20,9 & 24,4 \\
Ciclo 1 (2002-2003) & 292 & 1142 & 22,3 & 25,8 \\
Ciclo 2 (2003-2004) & 419 & 785 & 20,8 & 24,2 \\
Ciclo 3 (2004-2005) & 334 & 1078 & 20,9 & 24,2 \\
\hline
\end{tabular}

O efeito do tratamento estratégico, na seca, sobre o OPG e no número de teleóginas influenciou a performance dos animais, nesse período, nos dois sistemas de pastejo. Os animais dos tratamentos $\mathrm{C}_{3} \mathrm{e}_{4}$ e $\mathrm{R}_{3}$ tiveram ganho de peso significativamente superiores aos demais tratamentos nos respectivos sistemas de pastejo. Os animais tratados, nesse período, com uma aplicaçáo de levamisol $\left(\mathrm{C}_{2}, \mathrm{R}_{2}\right.$ e $\left.\mathrm{R}_{4}\right)$, tiveram médias de OPG intermediárias e significativamente diferentes dos grupos controle e tratados com endectocidas, mas o ganho médio de peso não diferiu significativamente dos obtidos nos animais controle $\left(\mathrm{C}_{1}\right.$ e $\left.\mathrm{R}_{1}\right)$ (Tabela 3).

Os acaricidas utilizados no período das águas têm ação somente sobre os ectoparasitos. Apesar disso, os grupos $\mathrm{C}_{3}$ e $\mathrm{C}_{4}$ e $\mathrm{R}_{3}$ continuaram com OPG significativamente menores, indicando efeito do tratamento anti-helmíntico estratégico, realizado na seca, durante o período das águas.

Dos tratamentos contra ectoparasitos realizados no período das águas, o fipronil $\left(\mathrm{C}_{4}\right.$ e $\left.\mathrm{R}_{4}\right)$ diminuiu significativamente o número de larvas de $D$. hominis em relaçáo aos animais controle $\left(\mathrm{C}_{1}\right.$ e $\left.\mathrm{R}_{1}\right)$ e aos tratados com rotenona $\left(\mathrm{C}_{2}, \mathrm{C}_{3}, \mathrm{R}_{2}\right.$ e $\left.\mathrm{R}_{3}\right)$. Os animais tratados com fipronil e rotenona estavam, nos dois sistemas de pastejo, com infestaçôes significativamente menores por moscados-chifres que os animais controle $\left(\mathrm{C}_{1}\right.$ e $\left.\mathrm{R}_{1}\right)$. $\mathrm{O}$ tratamento com fipronil diminuiu significativamente a infestação por carrapato em relação aos animais controle; e os tratados com rotenona estavam com médias intermediárias e não significativamente diferentes dos animais controle e tratados com fipronil (Tabela 3 ).

No período das águas, no pastejo contínuo, o grupo $\mathrm{C}_{4}$ tratado com fipronil ganhou mais peso; contudo, no pastejo rotacionado, os ganhos de peso foram semelhantes, exceto no tratamento $R_{2}$ com ganho significativamente menor que os demais (Tabela 3).

\section{Efeito de sistema de pastejo}

No período seco, a análise de contraste mostrou diferenças significativas, entre pastejo contínuo e rotacionado, no OPG, 259 e $166, \mathrm{P}=0,0001$ e, no número de larvas de $D$. hominis, 3,4 vs. $2,7, \mathrm{P}=0,0423$, respectivamente. No período das águas, no

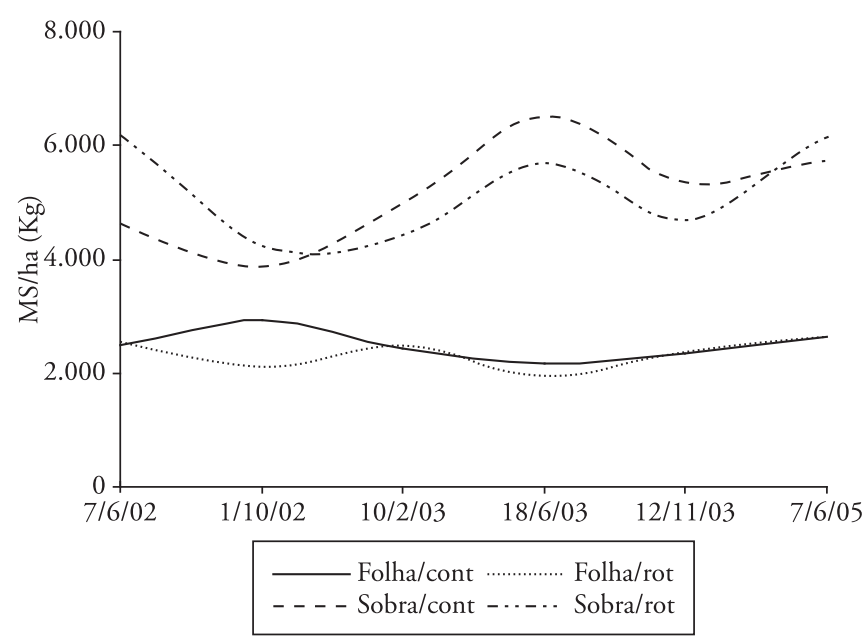

Figura 1. Produção de matéria seca em pastagem de Brachiaria brizantha sob pastejo contínuo e rotacionado, Mato Grosso do Sul. 
Tabela 3. Médias de OPG, de ectoparasitas e de ganho de peso de bovinos submetidos a diferentes estratégias de pastejo e tratamentos contra ecto e endoparasitas, durante os períodos seco e chuvoso.

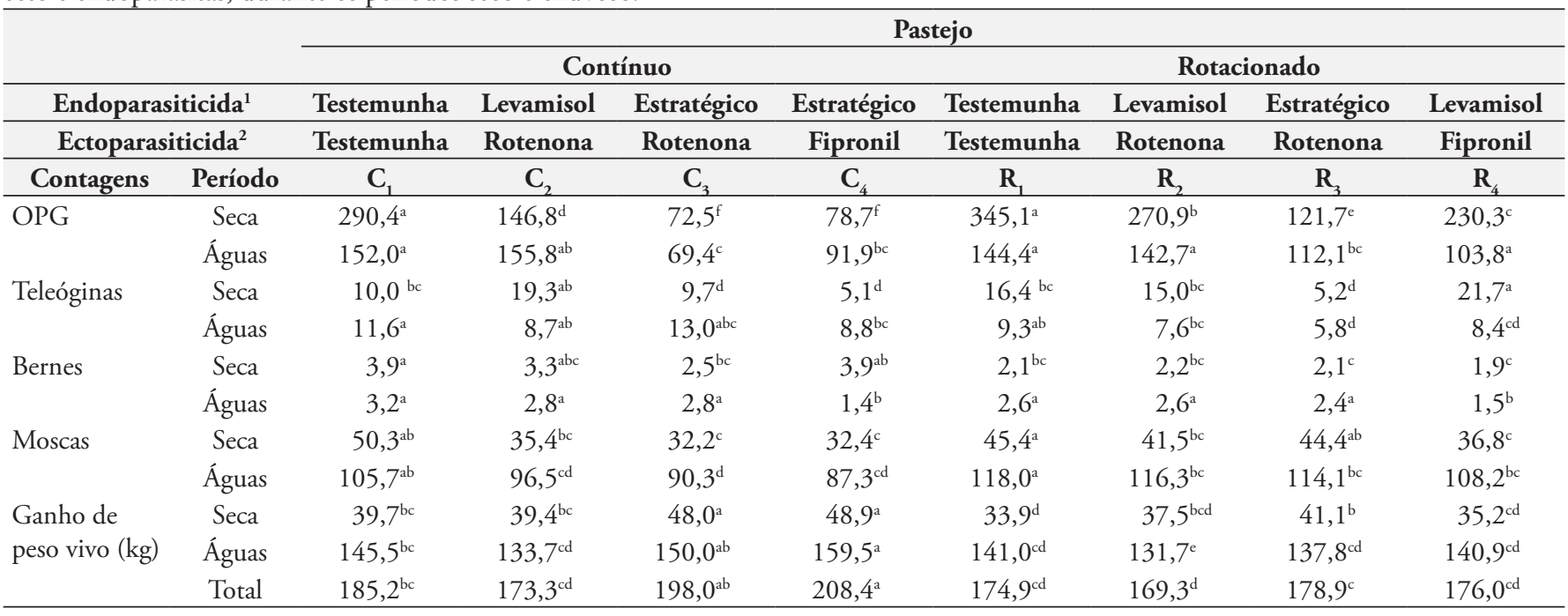

Para detalhes do experimento veja nota na Tabela 2. Médias na mesma linha com letras índices diferentes $\mathrm{P}<0,05$.

número de teleóginas, 9,2 e 6,9, P = 0,0005 e de mosca-dos-chifres, 94,9 e $114,1, \mathrm{P}=0,008$, respectivamente. Os animais sob pastejo contínuo ganharam mais peso que os sob pastejo rotacionado, no período seco ( 44,0 vs. $36,9 \mathrm{~kg}, \mathrm{P}=0,0034)$ e, no período chuvoso $(147,2$ vs. $137,8 \mathrm{~kg}, \mathrm{P}=0,0116)$.

\section{Tratamento levamisol vs. endectocida}

Durante a estaçáo seca os animais tratados com uma aplicaçáo de levamisol estavam mais parasitados por teleóginas, 22,2 vs. 7,2, $\mathrm{P}<0,0001$; com OPG maior, 208 vs. 97, $\mathrm{P}<0,0001$ e ganharam menos peso 38,4 vs. $44,6 \mathrm{~kg}, \mathrm{P}<0,0001$ que os tratados com três aplicações de endectocida, respectivamente. Na estação chuvosa estavam com OPG maior 101 vs. 90, $\mathrm{P}<0,01$ e ganharam menos peso 132 vs. $144 \mathrm{~kg}$. $\mathrm{P}<0,01$ que os tratados com três aplicaçóes de endectocida, durante a estação seca.

\section{Efeito da rotenona}

No período das águas as médias de ganho de peso dos grupos tratados com rotenona, tanto no pastejo contínuo como no rotacionado (Tabela 3), indicam um possível efeito negativo do extrato utilizado. A análise de contraste, nesse período, entre os grupos que receberam esse tratamento $\left(\mathrm{C}_{3}\right.$ e $\left.\mathrm{R}_{2}\right)$ e aqueles tratados com fipronil $\left(\mathrm{C}_{4}\right.$ e $\left.\mathrm{R}_{4}\right)$, mostrou diferença significativa nas médias de ganho de peso, 140,8 e 150,2 kg, $\mathrm{P}<0,002$, respectivamente; os grupos $\mathrm{C}_{2}$ e $\mathrm{R}_{2}$ tratados com rotenona também ganharam menos peso que os grupos controle $\mathrm{C}_{1}$ e $\mathrm{R}_{1}, 132,6$ vs. $143,2 \mathrm{~kg}$, $\mathrm{P}<0,001$.

Os animais tratados com rotenona estavam mais parasitados por larvas de Dermatobia, 2,7 que aqueles tratados com fipronil, $1,4, \mathrm{P}<0,0001$. Comparando-se os grupos tratados com rotenona $\left(\mathrm{C}_{2}\right.$ e $\left.\mathrm{R}_{2}\right)$ com o grupos controles $\left(\mathrm{C}_{1}\right.$ e $\left.\mathrm{R}_{1}\right)$, houve diferença significativa na média das infestaçóes por mosca-dos-chifres 106,4 vs. $111,9, \mathrm{P}=0,0132$.
Por fim, a análise no período das águas entre os grupos sob pastejo rotacionado, $\mathrm{R}_{1}$ (controle), $\mathrm{R}_{2}$ (rotenona) e $\mathrm{R}_{4}$ (fipronil) mostrou infestaçóes por berne semelhantes entre os grupos $R_{1}$ e $R_{2}, 2,6$ e 2,6 e menor no grupo $\mathrm{R}_{4,} 1,9, \mathrm{P}<0,01$. As infestaçóes por mosca-dos-chifres foram próximas entre os grupos, $\mathrm{R}_{1} \mathrm{R}_{2}$ e $\mathrm{R}_{4}$, mas significativamente maior nos animais controle 118,4, 116,3 e 108,2, P = 0,0226. A média de infestação por teleóginas foi maior no grupo controle, 5,6 mas não diferiu significativamente das médias dos grupos tratados com rotenona e fipronil, 3,9 e 3,6, respectivamente.

No ganho de peso, contudo, como nas análises anteriores, os animais tratados com rotenona $\left(\mathrm{R}_{2}\right)$ ganharam menos peso $131,7 \mathrm{~kg}, \mathrm{P}<0,05$, que os controles $\left(\mathrm{R}_{1}\right)$; e os tratados com fipronil $\left(\mathrm{R}_{4}\right), 141,0$ e $140,8 \mathrm{~kg}$, respectivamente.

Nos dois ciclos em que foram utilizados, os animais Braford estavam, tanto no período seco quanto no chuvoso, significativamente mais parasitados $(\mathrm{P}<0,05)$ que os da raça Brangus por carrapato, 16,3 e 8,5 vs. 11,5 e 7,5, por mosca-dos-chifres, 43,5 e 115,6 vs. 36,0 e 93,3, respectivamente, e mais parasitados na estaçáo chuvosa por larvas de Dermatobia 2,8 vs. 2,0. Por outro lado, estavam com o OPG menor, 152,5 e 97,0 vs. 236,5 e 145,9 e ganharam mais peso 50,3 e 150,2 vs. 30,3 e 134,8 kg que os da raça Brangus, na estação seca e chuvosa, respectivamente $(\mathrm{P}<0,05)$.

\section{Discussão}

\section{Ensaios in vitro e com animais estabulados}

O efeito acaricida, observado nas larvas e teleóginas, nos testes in vitro, se assemelha aos resultados obtidos por Pereira e Famadas (2004) com rotenona oriunda de raiz de Dahlstedtia pentaphylla. Esses autores observaram uma $\mathrm{DL}_{90}$ na diluição 1:85 para larvas e uma $\mathrm{EC}_{90}$ na diluição 1:10,1 para teleóginas, e concentraçóes obtidas a partir de uma solução padrão com uma parte de pó da raiz da planta para três do solvente. 
Com extrato da raiz da mesma planta, em animais infestados experimentalmente e mantidos a campo, Pereira e Famadas (2006) observaram, na diluição 1:10, uma diminuição de $76 \%$ três dias pós-tratamento. No presente estudo, nos animais experimentalmente infestados com 20.000 larvas nos dias -4 e, com 5.000 larvas nos dias 21 e 27 e tratados, nos dias 0 e 24 , não houve produção de teleóginas, com uma redução de $100 \%$, mas a ação acaricida ocorreu somente na fase de larva.

\section{Ensaio a campo - parasitismo e ganho de peso}

Independentemente do sistema de pastejo, o ganho médio de peso, observado nos três ciclos, de $298 \mathrm{~g} / \mathrm{animal} / \mathrm{dia}$ e $572 \mathrm{~g} / \mathrm{animal} / \mathrm{dia}$, na seca e na chuva, respectivamente, ocorreu conforme o esperado para esta região do Brasil Central. Apesar da disponibilidade alta de MS durante todo o período experimental, o ganho de peso refletiu a variação quali-quantitativa da pastagem e a idade dos animais (Figura 1).

No ensaio a campo o tratamento com rotenona, na estação chuvosa, não diminuiu significativamente o número de teleóginas, resultado que difere do obtido por Pereira e Famadas (2006). O ganho de peso menor, durante o período das águas, de aproximadamente $10 \mathrm{~kg}$ dos animais tratados com rotenona em relação aos controles e tratados com fipronil, nas três avaliaçóes testadas, apesar da baixa toxicidade dessa molécula para mamíferos (MASCARO et al., 1998), indica um possível efeito negativo do extrato da planta Lonchocarpus nicou. No pastejo contínuo, o grupo tratado estrategicamente contra endo e ecto parasitos $\left(\mathrm{C}_{4}\right)$ ganhou significativamente mais peso $(23 \mathrm{~kg})$ que o grupo controle $\left(C_{1}\right)$, mas, no pastejo rotacionado, o grupo $\left(\mathrm{R}_{3}\right)$ tratado estrategicamente contra endoparasitos náo teve ganho de peso superior ao grupo controle $\left(\mathrm{R}_{1}\right)$, devido ao efeito negativo do tratamento acaricida com o extrato de Lonchocarpus nicou no período chuvoso (Tabela 3).

Nos dois sistemas de pastejo, as infestaçóes por ecto e endo parasitas foram sempre próximas e as diferenças sem importância epidemiológica, mas a análise estatística mostrou resultados inconsistentes. Por causa da dispersão da mosca-dos-chifres, dos vetores da Dermatobia hominis, e da longevidade das larvas de carrapato no ambiente (SOUZA et al., 1993; FURLONG, 1998), esperavam-se médias semelhantes de parasitismo pelos ectoparasitos nos dois sistemas de pastejo. Também esperavam-se médias de OPG semelhantes e não significativamente maior no pastejo rotacionado no período seco (CATTO; BIANCHIN, 2007).

Apesar da disponibilidade semelhante de matéria seca, nos dois sistemas de pastejo (Figura 1), os animais sob pastejo contínuo ganharam mais peso na estação seca e chuvosa $(\mathrm{P}<0,05)$, possivelmente, pela queda da qualidade causada pela inflorescência da pastagem observada, principalmente, no sistema rotacionado.

$\mathrm{O}$ ganho de peso maior de $23 \mathrm{~kg}$ (Tabela 3) observado nos animais tratados com endectocida e fipronil $\left(\mathrm{C}_{4}\right)$ em relação ao grupo controle $\left(\mathrm{C}_{1}\right)$ é inferior aos $43 \mathrm{~kg}$ observado por Bianchin et al. (2007) também com animais cruzados, na mesma área experimental. Em ambos os estudos a disponibilidade de MS foi mantida alta (5 a 8 ton MS/ha), mas no estudo anterior
(BIANCHIN et al., 2007), os animais não foram arraçoados durante o período experimental, recebendo apenas $300 \mathrm{~g} / \mathrm{animal} / \mathrm{dia}$ de sal protéico na estação seca.

As médias de parasitismo por carrapato e larvas de berne nos grupos controles foram semelhantes em ambos os estudos e, as médias por mosca-dos-chifres, um pouco maior no presente estudo. A média de OPG (230) nos grupos controle, no presente estudo, foi bastante inferior em relação à média de 470 observada por Bianchin et al. (2007).

A relação entre os nematódeos gastrintestinais e os bovinos é complexa, e o efeito desses parasitas nos parâmetros produtivos do hospedeiro depende da interação de vários fatores, como estado imune do hospedeiro, nível nutricional, carga parasitária e espécies de parasitas envolvidas, entre outros. $\mathrm{O}$ arranjo desses fatores, que favorecem o parasita ou o hospedeiro, e o conhecimento da epidemiologia é que determinam a magnitude do efeito do controle das parasitoses na performance dos animais.

Segundo Magaya et al. (2000) em novilhos de 18 meses naturalmente infectados e tratados com: (A) anti-helmíntico mais suplemento de farelo de algodão; (B) somente anti-helmíntico; (C) somente farelo de algodão e (D) controle, observaram que os animais do grupo A e B estavam menos parasitados, mas os animais dos grupos A e $\mathrm{C}$ ganharam significativamente mais peso. $\mathrm{O}$ efeito do arraçoamento na tolerância de bovinos aos nematódeos, entre o desmame e os 24 meses, também foi observado por Soutello et al. 2002). Esses autores não observaram diferença significativa no ganho de peso entre grupos de animais arraçoados e não everminados (320 g/animal/dia) e não arraçoados e everminados (339 g/animal/dia), apesar da diferença significativa na média de OPG, $275 \times 31$, respectivamente. No mesmo período, o grupo arraçoado e everminado ganhou $453 \mathrm{~g} / \mathrm{animal} / \mathrm{dia}$ e o grupo controle, $251 \mathrm{~g} /$ animal/dia.

No presente estudo, em que os animais foram arraçoados, a diferença observada no ganho de peso vivo entre animais tratados e controle foi de 10\% (23 kg), enquanto Bianchin et al. (2007), na mesma área experimental, em animais da mesma faixa etária, observaram uma diferença de 16\% (43 kg), quando os animais não foram arraçoados durante o período experimental.

\section{Conclusóes}

O uso da rotenona na forma de extrato da raiz de Lonchocarpus nicou foi eficiente contra a infestação de larvas porém produziu insuficiente grau de atividade antiparasitária contra o carrapato Rhipicephalus (Boophilus) microplus nos testes in vitro e em animais experimentalmente infestados. Também não diminuiu significativamente as infestaçóes por teleóginas no ensaio a campo.

O sistema de pastejo rotacionado utilizado neste ensaio, com 30 dias de descanso da pastagem, não diminuiu o OPG.

Os animais da raça Braford durante o período experimental estavam mais parasitados por ectoparasitos, com menor número de ovos de nematódeos gastrintestinais e ganharam mais peso que os da raça Brangus.

O tratamento convencional anti-helmíntico e acaricida estratégico proporcionou significativo aumento do ganho de peso 
de bovinos por condicionar infecçôes/infestaçôes variáveis de leves a moderadas, na fase de recria.

\section{Agradecimentos}

Aos técnicos agrícolas Marco Antonio da Silva e Ronaldo Luiz da Silva pela colaboração na coleta de amostras, contagem de parasitos e exames laboratoriais.

\section{Referências}

BIANCHIN, I. et al. Effect of stocking rates and anthelminthic treatments on weight gains in weaned Nellore cattle on improved pasture in the Brazilian Cerrado. Tropical Animal Health and Production, v. 27, n. 1, p. 1-8, 1995.

BIANCHIN, I. et al. The effect of the control of endo and ectoparasites on weight gains in crossbred cattle (Bos taurus taurus $\times$ Bos taurus indicus) in the central region of Brazil. Tropical Animal Health and Production, v. 39, n. 4, p. 287-296, 2007.

BIANCHIN, I.; ALVES, R. G. O. Mosca-dos-chifres, Haematobia irritans: comportamento e danos em vacas e bezerros Nelore antes da desmama. Pesquisa Veterinária Brasileira, v. 22, n. 3, p. 109-113, 2002 .

CATTO, J. B.; BIANCHIN, I. Efeito de sistema de pastejo e de espécies forrageiras na contaminaçáo da pastagem e no parasitismo por nematóides gastrintestinais em bovinos de corte. Revista Brasileira de Saúde e Produçáo Animal, v. 8, n. 4, p. 343-353, 2007.

DRUMMOND, R. O. et al. Boophilus annulatus and Boophilus microplus: laboratory tests of insecticides. Journal Economic Entomology, v. 66, n. 1, p. 130-133, 1973.

EYSKER, M. et al. The effect of rotational grazing periods of one or two weeks on the build-up of lungworm and gastrointestinal nematode infections in cattle. Veterinary Quartely, v. 15, n. 1, p. 20-24, 1993.

FAO. Recommended methods for the detection and measurement of resistance of agricultural pests to pesticides. Tentative methods for larvae of cattle tick Rhipicephalus spp. FAO Plant Protection Bulletin, method n. 7 , v. 19 , p. $15-18,1971$.

FERNANDES, L. H. et al. Efeito do pastejo rotacionado e alternado com bovinos adultos no controle da verminose em ovelhas. Arquivos Brasileiro de Medicina Veterinária e Zootecnia, v. 56, n. 6, p. 733-740, 2004.

FURLONG, J. Poder infestante de larvas de Boophilus microplus (acari:ixodidae) em pastagem de Melinis minutiflora, Brachiaria decumbens e Brachiaria mutica. Ciência Rural, v. 28, n. 4, p. 635-640, 1998.

GORDON, H. M.; WHITLOCK, H. V. A new technique for counting nematode eggs in sheep faeces. Journal Council of Science Industry Research, v.12, p.50-52, 1939.
HAMMOND, A. C. et al. Effect of rotational vs continuous intensive stocking of Bahia grass on performance of Angus cows and calves and the interactions with sire type on gastrointestinal nematode burden. Journal Animal Science, v. 75, n. 9, p. 2291-2299, 1997.

KEITH, R. K. The differentiation of the infective larvae of some common nematode parasites of cattle. Australian Journal Zoology, v. 2, p. 223-235, 1953.

MAGAYA, A. et al. Effects of anthelmintic treatment and feed supplementation on grazing Tuli weaner steers naturally infected with gastrointestinal nematodes. Journal of the South African Veterinary Association, v. 71, n. 1, p. 31-37, 2000.

MASCARO, U. C. P. et al. Valores de $\mathrm{DL}_{50}$ em peixes e no rato tratados com pó de raízes de Derris spp e suas implicaçóes ecotoxicológicas. Pesquisa Veterinária Brasileira, v. 18 n. 2. p. 53-56, 1998.

PEREIRA, J. R.; FAMADAS, K. M. Avaliação “in vitro" da eficiência do extrato da raiz do timbó (Dahlstedtia pentaphylla) (Leguminosae, Papilionoidae, Millettiedae) sobre Boophilus microplus (Canestrini, 1887) na região do Vale do Paraíba, São Paulo, Brasil. Arquivos Instituto Biológico, v. 71, n. 4, p. 443-450, 2004.

PEREIRA, J. R.; FAMADAS, K. M. The efficiency of extracts of Dahlstedtia pentaphylla (Leguminosae, Papilionoidae, Millettiedae) on Boophilus microplus (Canestrini, 1887) in artificially infested bovines. Veterinary Parasitology, v. 142, n. 1-2, p. 192-195, 2006.

ROCHA, R. A. et al. Sheep and cattle grazing alternately: Nematode parasitism and pasture decontamination. Small Ruminant Research, v. 75, n. 2-3, p. 135-143, 2008.

SAS INSTITUTE. SAS/STAT user's guide. 4 ed. North Carolina: SAS Institute Inc., 1989. v. 2, 846 p.

SOUTELLO, R. V. G. et al. Influência do parasitismo e da suplementação protéica no desenvolvimento ponderal de novilhos mestiços Angus-Nelore e da raça Guzerá. Ciências Agrárias e da Saúde, v. 2, n. 1, p. 21-27, 2002.

SOUZA, A. P. et al. Poder infestante das larvas de Boophilus microplus (Can. 1887), em condições naturais, nos campos de Lages, SC, Brasil. Revista Brasileira de Parasitologia Veterinária, v. 2, n. 2, p. 93-98, 1993.

SOUZA, H. et al. Efeito de dois métodos de pastejo rotacionado no controle dos parasitas gastrintestinais e no desenvolvimento ponderal de cordeiros do nascimento ao desmame. Semina, v. 26, n. 1, p. 93-102, 2006.

TOZZI, A. M. G. A. A identidade do Timbó-verdadeiro: Deguelia utilis (A.C.Sm.) A.M.G.Azevedo (Leguminosae - Papilionoideae). Revista Brasileira de Biologia, v. 58, n. 3, p. 511-516, 1998.

WHARTHON, R. H.; UTECH, K. B. W. The relation between engorgement and dropping of Boophilus microplus (Canestrini) (Ixodidae) to the assessment of tick numbers on cattle. Journal Australian Entomological Society, v. 9, p. 171-182, 1970. 